\title{
Management of Common Newborn Emergencies
}

\author{
Roberto Calzada ${ }^{1}$, Adriana Yock-Corrales ${ }^{1 *}$ and Manuel Soto-Martínez ${ }^{2}$ \\ ${ }^{1}$ General Physician, Pediatric EmergencyDepartment, Hospital Nacional de Niños, Costa Rica \\ ${ }^{2}$ PediatricRespiratoryPhysician, Pediatric Respiratory Department, Hospital Nacional de Niños, Costa Rica
}

*Corresponding author: Adriana Yock-Corrales, Pediatric Emergency Department, Hospital Nacional de Niños, San José, Costa Rica.
Received Date: May 25, 2020

Published Date: May 29, 2020

\begin{abstract}
Patients in the neonatal period can present in the emergency department with many life-threatening conditions.Knowledge of these presentations by physicians that work in the emergency department is mandatory for the immediate approach of the critically ill infant. It is the responsibility of the emergency department team to identify these conditions and to stablish the best approach; this includes stabilization of the patient, differential diagnosis based, laboratory and images findings; and a well guided treatment. Serious bacterial infections, congenital cardiac disease, gastro intestinal emergencies (including malrotation with midgut volvulus and necrotizing enterocolitis), respiratory conditions, neurologic disorders and child abuse are the most common diagnosis in this type of scenarios. The main objective of this article is to review the most common conditions of the critical ill infant in the emergency department.
\end{abstract}

\section{Introduction}

Non-serious conditions are the cause of the majority of visits to the emergency department (ED) in these age group patients [1]. Although infection is the most reported cause of the ill appearance among neonates and young infants, there are other clinical conditions that have similar presentations and also represents serious entities of an unwell infant [2,3]. The ED personnel should be ready to identify conditions that increased the mortality in this population, and to have a step-approach to follow in this case without delaying treatment.

\section{Recognition and Approach of the Critically Ill Neonate}

\section{Clinical history}

The first step for any crucial diagnosis is the clinical history. The physician should always check for prenatal, perinatal and postnatal history. Prolonged membrane rupture or perinatal maternal fever is an important risk factor for sepsis. Prematurity and low birth weight are one of the major contributors to infant mortality $[4,5]$. Other important information is the Apgar score and need for resuscitation at birth, weight gain in the first week, frequency in urination and bowel movements, as well as feeding.Any change in the patient normal pattern could mean a serious condition that might need further evaluation.

\section{Physical examination}

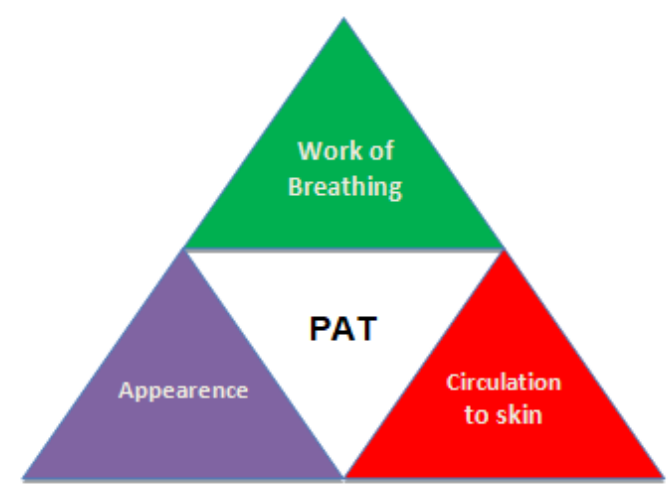

Figure 1 
A complete physical examination can help detecting anomalies that may risk the newborn life. Evaluation of neonatal size, weight, and vital signs as heart rate, respiratory rate, oxygen saturation level, blood pressure and temperature are necessary. The Pediatric Assessment triangle (PAT) is a well stablished method for rapid assessment that should be done in every child in the ED, this triangle includes theevaluation of the infant's appearance, work of breathing and circulation to skin [6,7] (Figure 1).

Evaluation of the airway and breathing is very important. Work of breathing, respiratory rate and auscultation is essential. The normal respiratory rate is 40 to 60 breaths per minute in neonates. Physicians should verify that the patient has adequate ventilation and oxygenation, as well as need for positioning and suctioning. Abnormal sounds (snoring, grunting, stridor, audible wheeze and any abnormal sounds) associated with signs of increase work of breathing (sniffing position, nasal flaring, retractions, paradoxical chest movements) has to be interpreted as signs of respiratory distress [8].

Circulation, including hydration status, capillary refill time (normal less than 2 seconds), and heart rate should be evaluated. The normal neonatal heart rate is between 120 and 160 beats per minute, and the systolic blood pressure 60 to $90 \mathrm{mmHg}$ [8]. Hypotension is a late finding in a patient with shock.

A direct guided neurological examination should be performed. Some aspects that should be included are muscular tone, cranial nerves, primitive reflexes and consciousness (Table1). Seizures may indicate abnormalities including low glucose and abnormal electrolyte levels, central nervous system infections, and metabolic disease [9].

Table 1: Common developmental reflexes in the newborn.

\begin{tabular}{|c|c|c|}
\hline Reflex & Time of Appearance & Age of Disappearance \\
\hline Moro & $34-36$ weeks & $5-6$ months \\
\hline Asymmetric tonic neck reflex & $38-40$ weeks & $2-3$ months \\
\hline Trunk incurvation (Galant) & $38-40$ weeks & $1-2$ months \\
\hline Palmar Gasp & $38-40$ weeks & $5-6$ months \\
\hline Palmar Gasp & $38-40$ weeks & $9-10$ months \\
\hline Rooting & $38-40$ weeks & $2-3$ months \\
\hline
\end{tabular}

Assessment of the abdomen and genitourinary tract is also something that has to be done. The liver border is frequently palpated approximately $1 \mathrm{~cm}$ below the right costal margin. The umbilical cord has to be inspected looking for signs of infection and bleeding. Male infants should be evaluated for hypospadias or other urethral anomalies, inguinal hernias, varicoceles, hydroceles and undescended testis [10].

Skin conditions are a frequent consultation in the ED. The most common is erythema toxicum neonatorum, occurring in almost 20$50 \%$ of the newborns; is a common pustular eruption seen in term neonates within the first 72 hours of life that resolves spontaneously within one week [11]. Abnormal skin color should be evaluated, especially when jaundice appears. Jaundice can be associated with life threatening illness like sepsis or metabolic disease [12].

\section{Systematic approach}

The first step in assessing the critically ill neonate is the first impression with the PAT. The first impression includes aparience, respiratory effort and circulation to the skin. After PAT, the primary assessment follows with evaluation of airway, breathing, circulation, disability and exposure (ABCDE). The physician has to check for vital signs, placement of a cardiac monitor and pulse oximeters; bedside testing of blood glucose should be done promptly [13]. Delivery of oxygen by high flow mask may be sufficient to reverse hypoxia in the ill neonate. If no peripheral intravenous lines can be established, either an intra-osseous line or umbilical catheter must be placed. When saline boluses are required, the physician initially should begin with $5-10 \mathrm{ml} / \mathrm{kg}$ and then check on vital and clinical signs of perfusion.Normal neonatal glucose goes above $35-40 \mathrm{mg} /$ $\mathrm{dl}$, below that number is considering hypoglycemia [14] (Figure 2).

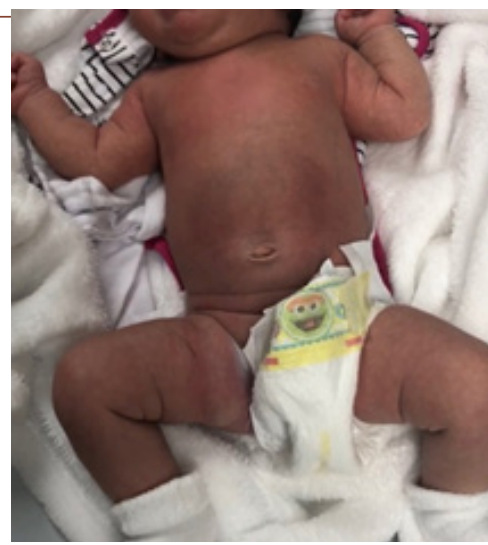

Figure 2: Assessment of Circulation to the skin in PAT Newborn patient with cyanosis.

\section{Laboratory testing}

Laboratory tests are needed when there is a clinical suspicion, but in the ill neonate there are unspecific signs and symptoms that vary alongside the different diseases. Electrolytes, serum glucose, and calcium level; a complete blood cell count (CBC); pro-thrombin time (PT); partial thromboplastin time (PTT); and blood cultures should be considered once IV access. Other tests may be considered depending on the differential diagnosis [3]. 
Infectious disease emergencies:Congenital infections and neonatal sepsis are important conditions in this age group.It is estimated that $12.5 \%$ of febrile infants have a serious bacterial infection and the incidence in pediatric population younger than 28 days may be as high as $20 \%[15,16]$.

\section{Neonatal sepsis}

Neonatal sepsis can be associated withhigh mortality and morbidity. It can be classified in early onset sepsis (EOS) and late onset sepsis (LOS). EOS is present in the first week of life and is associated with vertical transmission, being the vaginal bacteria flora of the mother the most common source [17]. The risk factors are prolonged membrane rupture ( $>18$ hours), maternal age $>35$ years, cesarean section, chorioamniotis, maternal B streptococcal colonization, maternal fever and presence of sexually transmitted disease. Group B streptococcus and E. coli are the most common bacteria in early onset sepsis, alongside with other microorganism found in Table 2 [18].

Table 2: Most common agents in EOS and LEOS.

\begin{tabular}{|c|c|}
\hline Early Onset Sepsis Common Agents & Late Onset Sepsis Common Agents \\
\hline Group B streptococcus and E. coli (most frequent) & CoNS \\
\hline Lysteriamonocytogened & Enteroccoccussp \\
\hline Klebsiella & \\
\hline Enterococcus & \\
\hline Non-group D $\alpha$-hemolytic streptococcus & \\
\hline V H. influenza & \\
\hline
\end{tabular}

LOS is presented from day 7 to 28 days of life and it is not usually associated with complications in the obstetric scenario, therefore these neonates may have risk factors that can be identified as triggers. For example, disruption of the skin or mucosa due to

Table 3: Clinical Presentation of a Septic Neonate.

\begin{tabular}{|c|}
\hline Clinical Presentation of a Septic Neonate \\
\hline Hyperthermia (more common in full term infant) \\
\hline Irregularity Hypothermia (more common than fever in Preterm) \\
\hline Neurologic and behavioral changes (Lethargy, irritability) \\
\hline Skin (poor peripheral perfusion, cyanosis, pallor, petechia, rashes) \\
\hline Gastrointestinal problems (decrease oral intake, vomiting, diarrhea) \\
\hline Cardiopulmonary (tachycardia, respiratory distress, apnea, and hypotension) \\
\hline Metabolic disorders (Hypoglycemia, hyperglycemia, or metabolic acidosis) \\
\hline Focal infections (Cellulitis, omphalitis, conjunctivitis, otitis media or osteomyelitis) \\
\hline
\end{tabular}

Clinical presentation: Clinical manifestations vary from subtle symptoms to septic shock. Most of the signs and symptoms are nonspecific and are listed in Table 3. The physical examination should look for the source of infection; changes in basal temperature are the most common clinical finding. In full term infants hyperthermia is more common than hypothermia. Lethargy, irritability, and decreased oral intake are important findings related to neonates with a septic condition [19]. It is estimated that 85 percent of newborns with EOS, have signs of respiratory distress (tachypnea, grunting, flaring, use of accessory muscles).

Management and treatment of neonatal sepsis: Management should start with the evaluation of ABCDE with interventions depending on the abnormality found. Standard laboratory tests for the neonate with suspected sepsis are described in table 4 . The immature-neutrophil to total neutrophil ratio greater than 0.2 is 60 to $90 \%$ sensitive and $70 \%-80 \%$ specific for the diagnosis of invasive procedures (intravascular catheter) increases the risk of late-onset infection.In LOS, Gram-positive bacteria are the most common, in this case CoNS, S.aureus and Enterococcus species are the ones with general higher incidence. 
count (ANC). If any patient does not complete at least one of the criteria that is listed in the algorithm for low risk, it is immediately

classified as high risk and needs a complete diagnostic evaluation $[16,20]$.

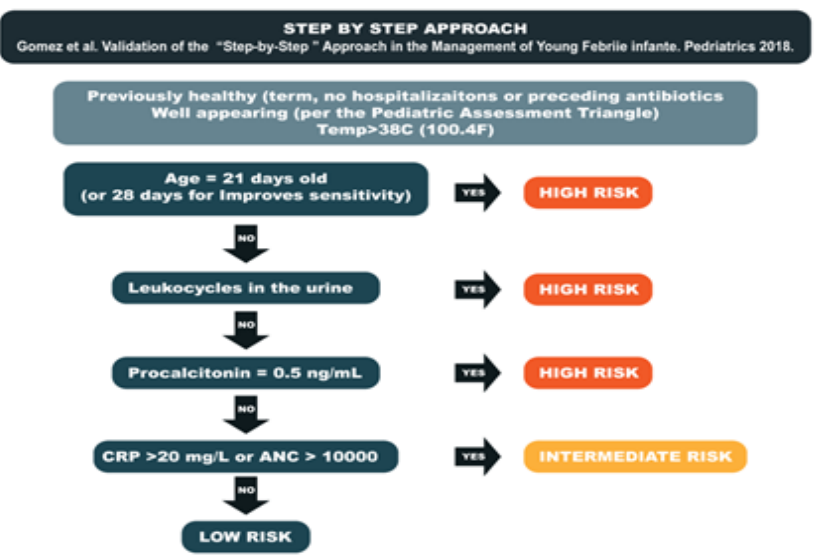

Figure 3: Step-by-step approach Adapted from Gomez B, Mintegi S, Bressan S, et al. [20].

Treatment with empiric antibiotics should be started. Ampicillin and gentamycin are the preferred empiric therapy. If there is a need to add another antibiotic a third-generationcephalosporin can be added depending on the antibiotic resistance and type of infection. In cases of LOS it its recommended coverage with vancomycin combined with aminoglycoside [21,22].

\section{Meningitis}

Bacterial meningitis in children is one of the most challenging and high-risk condition in the ED. Group B Streptococcus (GBS) and Escherichia coli are the most common causative agents in neonates and mortality rate is around 6.9\% [23]. Listeria monocytogenes, non-typeable $\mathrm{H}$ influenzae, and group A Streptococcus are uncommon in this period of life. Neonates, young infants, and immunocompromised older children are at highest risk. Nowadays, the use of intrapartum antibiotics to prevent neonatal GBS infection has reduced its prevalence in the neonatal period.Common bacterial meningitis pathogens are: Group B Streptococcus (39\%), Gram-negative bacilli (32\%), Streptococcus pneumonia (14\%) and Neisseria meningitidis (12\%) [23].

Clinical presentation: Fever, vomiting, seizures, and altered mental status are the predominant signs of meningitis in the neonatal age, symptoms sometimes can be subtle so every patient with less than 28 days with suspected sepsis should always be screened for meningitis [23].

Management and treatment: $\mathrm{ABC}^{\prime} \mathrm{s}$ (airway, breathing, and circulation) is a standard procedure on the initial evaluation and stabilization of the patient, alongside with intravenous (IV) and antibiotics [23]. Lumbar puncture with CSF analysis and culture, peripheral blood cultures and other specific laboratory markers such as procalcitonin are needed to increase the sensitivity of the diagnosis confirmation by laboratory test. According to some literature, the median CSF WBC count was significantly higher in infants aged less than 28 days ( 3 cells/mcL; 95th percentile, 19 cells/mcL) than in infants aged 29 to 56 days ( 2 cells/mcL; 95 th percentile, 9 cells $/ \mathrm{mcL}, \mathrm{P}<.001$ ) [23].

Appropriate initial empiric coverage includes ampicillin and Cefotaxime. It is not common for neonates to have meningitis caused by methicillin-resistant Staphylococcus aureus (MRSA) or resistant S. pneumonia, however if there is a suspected meningitis by one of this two agents, vancomycin can also be added. Finally, there is limited evidence for the use of routine adjuvant steroids, therefore it is not recommended for treatment of neonatal meningitis [23].

\section{Neonatal herpes (HSV)}

Neonatal herpes is an uncommon infection occurring in 1 of every 32000 deliveries and presents between the second and third week of life. The most common risk factor is birth to an HSV infected mother; it represents a higher risk being born with vaginal delivery in mothers with primary genital infection [24].

Three clinical manifestations are important for the prediction of morbidity and mortality. First the disseminated type, in which multiple organs including the liver, lung, adrenal glands, skin, eye, and brain (60 to $75 \%$ of disseminated HSV) are involved; and it represents $25 \%$ of HSV infections.The second is CNS infection without disseminated disease, but can also be associated with skin, eyes and mouth manifestations; it occurs in 30\% of HSV infections. The third one is the skin, eye, or mouth disease and it represents approximately $45 \%$ of HSV disease; this one does not include CNS or disseminated HSV infection. Risk factors for neonatal HSV are: duration of rupture membranes, integrity of cutaneous barrier, maternal antibody status, vaginal delivery and type of HSV (HSV 1 vs. 2) $[25,26]$. 
Table 4: Standard laboratory and image tests for suspected neonatal sepsis.

Standard Laboratory and Image Tests for Suspected Neonatal Sepsis

\begin{tabular}{|c|}
\hline Complete blood count (CBC) \\
\hline Urinalysis \\
\hline Cerebrospinal fluid (CSF) \\
\hline Blood, urine and CSF culture \\
\hline Creaction protein (CRP) \\
\hline Calcium level \\
\hline Electrolyte \\
\hline PT/PTT \\
\hline Chest radiograph \\
\hline
\end{tabular}

Table 5: Recommended antibiotics and dosages for neonatal sepsis.

\begin{tabular}{|c|c|}
\hline Antibiotic & Doses \\
\hline \multirow{6}{*}{ Ampicilin } & s2000gr: \\
\hline & $0-7$ days: $100 \mathrm{mg} / \mathrm{kg} /$ day $12 \mathrm{H}$ \\
\hline & 8-28days: $150 \mathrm{mg} / / \mathrm{kg} /$ day $8 \mathrm{H}$ \\
\hline & $\geq 2000$ gr: \\
\hline & $0-7$ days: $150 \mathrm{mg} / \mathrm{kg} /$ day $8 \mathrm{H}$ \\
\hline & 8-28days: $200 / \mathrm{kg} /$ day $6 \mathrm{H}$ \\
\hline \multirow{9}{*}{ Gentamycin } & $\leq 32$ weeks Gestational Age \\
\hline & $0-14$ days: $15 \mathrm{mg} / \mathrm{kg} /$ day $48 \mathrm{H}$ \\
\hline & $>14$ days: $15 \mathrm{mg} / \mathrm{kg} /$ day $24 \mathrm{H}$ \\
\hline & 32-36 weeks Gestational Age \\
\hline & $0-7$ days: $15 \mathrm{mg} / \mathrm{kg} /$ day $24 \mathrm{H}$ \\
\hline & 7 days: $15 \mathrm{mg} / \mathrm{kg} /$ day $24 \mathrm{H}$ \\
\hline & $\geq 36$ weeks: \\
\hline & $0-7$ days: $15 \mathrm{mg} / \mathrm{kg} /$ day $24 \mathrm{H}$ \\
\hline & $>7$ days: $17.5 \mathrm{mg} / \mathrm{kg} /$ day $24 \mathrm{H}$ \\
\hline \multirow{6}{*}{ Cefotaxime } & $\leq 2000 \mathrm{gr}:$ \\
\hline & $0-7$ days: $100 \mathrm{mg} / \mathrm{kg} /$ day $12 \mathrm{H}$ \\
\hline & $8-28$ days: $150 \mathrm{mg} / \mathrm{kg} /$ day $8 \mathrm{H}$ \\
\hline & $\geq 2000$ gr: \\
\hline & $0-7$ days: $100 \mathrm{mg} / \mathrm{kg} /$ day $12 \mathrm{H}$ \\
\hline & 8-28days: $150 \mathrm{mg} / \mathrm{kg} /$ day $8 \mathrm{H}$ \\
\hline \multirow{6}{*}{ Vancomycin } & According to serum creatinine concentrations in a neonate $\geq 28$ weeks gestational age \\
\hline & $<0.7: 15 \mathrm{mg} / \mathrm{kg} /$ day $12 \mathrm{H}$ \\
\hline & $0.7-0.9: 20 \mathrm{mg} / \mathrm{kg} /$ day $24 \mathrm{H}$ \\
\hline & $1-1.2: 15 \mathrm{mg} / \mathrm{kg} /$ day $24 \mathrm{H}$ \\
\hline & $1.3-1.6: 10 \mathrm{mg} / \mathrm{kg} /$ day $24 \mathrm{H}$ \\
\hline & $>1.6: 15 \mathrm{mg} / \mathrm{kg} /$ day $48 \mathrm{H}$ \\
\hline \multirow{6}{*}{ Acyclovir } & s2000gr: \\
\hline & $0-7$ days: $40 \mathrm{mg} / \mathrm{kg} /$ day $12 \mathrm{H}$ \\
\hline & 8-28days: $60 \mathrm{mg} / \mathrm{kg} /$ day $8 \mathrm{H}$ \\
\hline & $\geq 2000$ gr: \\
\hline & $0-7$ days: $60 \mathrm{mg} / \mathrm{kg} /$ day $8 \mathrm{H}$ \\
\hline & 8-28days: $60 \mathrm{mg} / \mathrm{kg} /$ day $8 \mathrm{H}$ \\
\hline
\end{tabular}


HSV cultures, PCR and whole blood sample are recommended. Laboratory definitive diagnosis is made by the isolation of HSV through culture, but PCR for HSV detection is more sensitive than viral culture in the CSF and blood, therefore it is the preferred test for disseminated and central nervous system HSV presentation. Tzanck test and detection of HSV antigen by direct immunofluorescence assay are not sensitive for HSV infection, therefore it is not recommended and should be avoided [27]. Treatment should start with supportive care, initial empiric broad spectrum antibiotics and administration of acyclovir. Initiation of treatment has shown to decrease mortality from 90 to $31 \%$ (Table 5).

Gastrointestinal emergencies (GI): There are clinical manifestations of the GI tract that may increase the probability of a serious illness.Vomiting (especially bilious), diarrhea, GI bleeding, and jaundice alongside with hemodynamic instability are symptoms that should raise concern in an ED. Malrotation in neonates including volvulus and duodenal obstruction, necrotizing enterocolitis and biliary atresia are some of the most common GI emergencies in the newborn period.

\section{Intestinal malrotation (volvulus and duodenal obstruction)}

Volvulus occurs when the small bowel twists around the superior mesenteric artery compromising its vascularity and producing small bowel ischemia. It is estimated that one-third of children with malrotation in the neonatal period, are at risk of presenting a volvulus [21]. In neonates, malrotation can also be presented as duodenal obstruction. It is produced by Ladd bands which cross the duodenum or by association of duodenal atresia and stenosis [28-30].

Clinical presentation: Volvulus usually presents with bilious vomiting and abdominal distention. It is common an acute presentation, but it can also be presented in a chronic way with episodic vomiting and abdominal pain, suggesting intermittent volvulus. The symptoms may vary, when the infant is younger at the time of presentation. Other symptoms include, loss of appetite, apneas, constipation and poor growth (31) The necrotic bowel can cause a third space fluid losses and also septic shock, with hemodynamic compromise. On the other hand, even though duodenal obstruction shares a similar vomiting characteristic (bilious), it is usually presented without abdominal distension. In a neonate, bilious vomiting is a surgical emergency until proven otherwise [29].

Management and treatment: When malrotation is suspected a complete blood cell count, electrolytes, blood urea, nitrogen, creatinine and blood group should be taken. Usually these patients are presented with dehydration, acidosis and elevated WBC [28]. The diagnostic test of choice is an upper gastrointestinal (UGI) study, which has a sensitivity of $96 \%$ for malrotation. Some positive signs of malrotation are the classic bird-beak sign and the corkscrew pattern in the dilated proximal duodenum with contrast.
Abdominal radiographs findings are not specific, but a distended bubble of air in stomach and duodenum with gasless abdomen are common findings in malrotation. Free air may be observed when there is a perforated segment from the ischemic bowel [28].

Initial treatment should be focused in fluid and electrolyte replacement and a nasogastric tube should be place.The definite treatment is the surgical resolution and antibiotics are needed to be administered if there are signs of peritonitis and shock [32].

\section{Necrotizing enterocolitis}

Necrotizing enterocolitis (NEC) is one of the most common gastrointestinal emergencies in the neonatal period and is usually seen in premature infants. It is common in the first 10 days of life and it consists in an ischemic necrosis of the intestinal mucosa associated with severe inflammation, invasion of enteric gas forming organisms, and dissection of gas into the bowel wall and portal venous system. It is a condition with high mortality, overall between $20 \%$ and $40 \%$. Its etiology is multifactorial [33].

Clinical presentation: Usually it is presented in preterm infants, although a $10 \%$ of cases occur in term newborns. (ref) The most frequent sign of NEC is an acute change in feeding tolerance with association of other clinical manifestations like ill appearance infant, with irritability, lethargy, anorexia, bloody stools and distension of the abdomen.

Management and treatment: Laboratory findings can be helpful in making the diagnosis of NEC. Findings are often anemia with leukocytosis, thrombocytopenia, evidence of disseminated intravascular coagulopathy (DIC), and in $20 \%$ of cases a positive blood culture. Also, electrolytes abnormalities can be present $[33,34]$.

For diagnostic issues, a plain radiograph of the abdomen is usually used to confirm the diagnosis of NEC with intraluminal gas, portal venous gas, free intra-peritoneal gas, and dilated loops of bowel, bowel wall thickening, and perforation which can occur in $12 \%-30 \%$ of patients. Ultrasonography has become a very useful tool in these cases because it aloud to detect free fluid [33].

Treatment of NEC includes an orogastric or nasogastric tube, antibiotics with anaerobic and gram-negative coverage (ampicilin, gentamycin, metronidazole), and aggressive hydration. Surgical intervention is indicated when pneumoperitoneum is present. Patients with NEC but without pneumoperitoneum can be followed up with repeated radiographs every 6 to 8 hours to check on NEC progression [3].

Neurological emergencies in neonates: Neurologic emergencies in a newborn can be manifested with unspecific and subtle symptoms, for example changes in the feeding pattern only.

\section{Seizures}

Neonatal seizures are often difficult to treat. It usually addresses a neurological specific condition, most commonly 
perinatal hypoxia-ischemia which accounts for approximately 50 $60 \%$, and usually starts in the first 24 hours after birth. Mortality ranges from 15 - 40\% [37]. Intracranial infections are responsible for $5 \%$ to $10 \%$ of neonatal seizures. Nonbacterial etiologies include toxoplasmosis, cytomegalovirus, and herpes simplex. Bacterial infections include a group already discussed earlier. Any infant with symptoms of sepsis should have a septic work-up

Table 6: Causes of Neonatal seizures.

\begin{tabular}{|c|c|c|}
\hline \multicolumn{3}{|l|}{ Causes of Neonatal Seizures } \\
\hline First Day of Life & Second Day of Life & Day 4 to 6 Months of Age \\
\hline Anoxia/hypoxia & Benign familial neonatal seizures & Benign idiopathic neonatal seizures \\
\hline Drugs & Congenital anomalies or development brain disorders & Congenital anomalies or development brain disorders \\
\hline Hypoglycemia/hyperglycemia & Drug withdraw & Drug withdraw \\
\hline Infection & Hyperphosphatemia & Hyperphosphatemia \\
\hline Intracranial hemorrhage & Hypertension & Hypertension \\
\hline Pyridoxine deficiency & Hypocalcemia & Hypocalcemia \\
\hline \multirow[t]{5}{*}{ Trauma } & Hypoglycemia & Hypoglycemia \\
\hline & Hyponatremia/ hypernatremia & Hyponatremia/ hypernatremia \\
\hline & Inborn errors of metabolism & Inborn errors of metabolism \\
\hline & Sepsis & Sepsis \\
\hline & Trauma & \\
\hline
\end{tabular}

Management and treatment: In the immediate care of a seizure the physician should first prioritized the stabilization of the airway, followed by breathing and circulation status (ABC's). If the respiratory system is compromised, supplementation of oxygen should be administered and getting blood glucose measurement is essential. If hypoglycemia is documented a bolus of $10 \%$ dextrose of $2-4 \mathrm{ml} / \mathrm{kg}$ should be indicated [41].

Laboratory tests should include guided causes of differential diagnosis such as metabolic disorder (glucose, sodium, calcium and magnesium levels). Other tests may include hematocrit, electrolytes, blood urea and nitrogen, phosphate, serum ammonia, blood gases and possibly blood cultures and lumbar puncture [12].

The first line of treatment in seizures is benzodiazepines like Lorazepam. If the seizure does not stop second line treatment is

Table 7: Pharmaceutical management of neonatal seizures. (including blood, urine, and cerebrospinal fluid (CSF) cultures. [38] Intracranial hemorrhage account for $10 \%$ of all cases, specially matrix intraventricular hemorrhages, and metabolic disturbances. Inborn errors of metabolism like a defect in pyridoxine metabolism might produce seizures in the neonatal period that will not ceased with antiepileptic drug therapy [38-40]. Causes of seizures in the neonatal period are shown in Table 6.

\begin{tabular}{|c|c|}
\hline \multicolumn{2}{|c|}{ Pharmaceutical Management of Neonatal Seizures } \\
\hline Drug & Dosage \\
\hline Benzodiazepines & $0.05-0.1 \mathrm{mg} / \mathrm{kg} \mathrm{IV}$ \\
\hline Lorazepam & $0.2-0.3 \mathrm{mg} / \mathrm{kg} \mathrm{IV} \mathrm{or} 0.5 \mathrm{mg} / \mathrm{kg} \mathrm{rectal}$ \\
\hline Diazepam & $0.1 \mathrm{mg} / \mathrm{kg} \mathrm{IV}$ \\
\hline Midazolam & Infusion $1-18 \mathrm{mcg} / \mathrm{kg} / \mathrm{min}$ \\
\hline & $20 \mathrm{mg} / \mathrm{kg} / \mathrm{IV}$ initially then repeat $10 \mathrm{mg} / \mathrm{kg} \mathrm{IV} \mathrm{q} 10 \mathrm{~min}$ (maximum of $50-60 \mathrm{mg} / \mathrm{kg})$ \\
\hline Phenobarbital & $15-20 \mathrm{mg} / \mathrm{kg} \mathrm{IV}$ \\
\hline & \\
\hline Phenytoin & \\
\hline
\end{tabular}




\section{Conclusion}

Many neonatal serious conditions may vary in presentation, but most of them are initially non-specific. The promptly recognition and knowledge of atypical features can improve the approach and give an earlier diagnosis. Every ED should always stablish an early communication with the pediatric or neonatal unit for a possible transfer in the second part of this article respiratory and cardiological conditions will be reviewed.

\section{Acknowledgement}

None.

\section{Conflict of Interest}

No conflict of interest.

\section{References}

1. Calado CS, Pereira AG, Santos VN, Castro MJ, Maio JF (2009) What brings newborns to the emergency department?: a 1-year study. Pediatr Emerg Care 25(4): 244-248

2. DePorre A, Aronson P, McCulloh R (2017) Facing the ongoing challenge of the febrile young infant. Crit Care. 21(1): 68.

3. Claudius I (2010) An Evidence-Based Review of Neonatal Emergencies Pediatr Emerg Med Pract 7: 8-9.

4. Matthews TJ, MacDorman MF, Thoma ME (2015) Infant Mortality Statistics From the 2013 Period Linked Birth/Infant Death Data Set. Natl Vital Stat Rep 64(9): 1-30.

5. Watkins J, Kotecha S, Kotecha S (2016) All-Cause Mortality of Low Birthweight Infants in Infancy, Childhood, and Adolescence: Population Study of England and Wales. PLOS Med 13(5): e1002018.

6. Giesinger R, McNamara PJ (2016) Hemodynamic instability in the critically ill neonate: An approach to cardiovascular support based on disease pathophysiology. Semin Perinatol 40(3): 174-188

7. Corrales AY, Starr M (2010) Assessment of the unwell child. Aust Fam Physician 39(5): 270-275.

8. Skillman HE, Mehta NM (2012) The Critically Ill Child. Curr Opin Crit Care 18(2):192-8.

9. Pisani F, Spagnoli C (2016) Neonatal Seizures: A Review of Outcomes and Outcome Predictors. Neuropediatrics 47(1): 12-19.

10. Lewis ML (2014) A comprehensive newborn examination: part II. Skin, trunk, extremities, neurologic. Am Fam Physician 90(5): 297-302.

11. Reginatto FP, Muller FM, Peruzzo J, Cestari T (2017) Epidemiology and Predisposing Factors for Erythema Toxicum Neonatorum and Transient Neonatal Pustular: A Multicenter Study. Pediatric Dermatology 34(4): 422-426.

12. McCollough M, Sharieff GQ (2002) Common complaints in the first 30 days of life. Emerg Med Clin North Am 20(1): 27-48.

13. Giesinger R, McNamara PJ (2016) Hemodynamic instability in the critically ill neonate: An approach to cardiovascular support based on disease pathophysiology. Semin Perinatol 40(3):174-188.

14. Committee on Fetus and Newborn, Adamkin D (2011) Postnatal glucose homeostasis in late-preterm and term infants. Pediatrics 127(3): 575579.

15. Wynn JL, Wong HR, Shanley TP, Bizzarro MJ, Saiman L, et al. (2014) Time for a neonatal-specific consensus definition for sepsis. Pediatr Crit Care Med 15(6): 523-528.

16. Rouhani A, Claudius I, Behar S, Mason J, Grock A (2018) Risk Stratifying Febrile Infants: A Moving Target. Ann Emerg Med 71(2): 217-219.
17. Cortese F, Scicchitano P, Gesualdo M, Filaninno A, De Giorgi E, et al. (2015) Early and Late Infections in Newborns: Where Do We Stand? A Review. Pediatr Neonatol 57(4): 265-273.

18. Stoll BJ, Hansen NI, Sánchez PJ, Faix RG, Poindexter BB, et al. (2011) Early onset neonatal sepsis: the burden of group B Streptococcal and E. coli disease continues. Pediatrics 127(5): 817-26.

19. Nizet V, Klein JO (2016) Bacterial sepsis and meningitis. In: Infectious diseases of the Fetus and Newborn Infant, $8^{\text {th }}$ edn, Remington JS, et al (Eds), Elsevier Saunders, Philadelphia, pp. 217.

20. Gomez B, Mintegi S, Bressan S, Da Dalt L, Gervaix A. et al. (2016) Validation of the "step-by-step" approach in the management of young febrile infants. Pediatrics 138(2): e20154381.

21. John S Bradley (2014) Nelson's Pediatric Antimicrobial Herapy. $\left(20^{\text {th }}\right.$ edn), American Academy of Pediatrics, United States.

22. Obiero CW, Seale AC, Berkley JA (2015) Empiric treatment of neonatal sepsis in developing countries. Pediatr Infect Dis J 34(6): 659-661.

23. Posadas E, Fisher J (2015) Pediatric Bacterial Meningitis: An Update on Early Identification and Management. Pediatr Emerg Med Pract 15(11): 1-23.

24. Pinninti SG, Kimberlin DW (2013) Maternal and neonatal herpes simplex virus infections. Am J Perinatol 30: 113-119.

25. Enright AM, Prober CG (2002) Neonatal herpes infection: diagnosis, treatment and prevention. Semin Neonatol 7(4): 283-291.

26. Whitley RJ, Corey L, Arvin A, Lakeman FD, Sumaya CV, et al. (1988) Changing presentation of herpes simplex virus infection in neonates. J Infect Dis 158(1): 109-116.

27. Caviness AC, Demmler GJ, Selwyn BJ (2008) Clinical and laboratory features of neonatal herpes simplex virus infection: a case-control study. Pediatr Infect Dis J 27(5): 425-430.

28. Ratnayake K, Kim TY (2014) Evidence-based management of neonatal vomiting in the emergency department. Pediatr Emerg Med Pract 11(11): $1-20$

29. Nehra D, Goldstein AM (2011) Intestinal malrotation: varied clinical presentation from infancy through adulthood. Surgery 149(3): 386-393.

30. Fonkalsrud E (2003) Rotational anomalies and volvulus. In: Principles of Pediatric Surgery, O'Neill JA et al. (Ed), Mosby, St. Louis.

31. Brousseau T, Sharieff GQ (2006) Newborn emergencies: the first 30 days of life. Pediatr Clin North Am 53: 69-84.

32. Liu LM, Pang LM (2001) Neonatal surgical emergencies. Anesthesiol Clin North America 19(2): 265-286

33. Lim JC, Golden JM, Ford HR (2015) Pathogenesis of neonatal necrotizing enterocolitis. Pediatr Surg Int 31: 509-518.

34. Kenton A (2005) Severe thrombocytopenia predicts outcome in neonates with necrotizing enterocolitis. J Perinatol 25(1): 14-20.

35. Park E, Pearson NM, Pillow MT, Toledo A (2014) Neonatal endocrine emergencies: a primer for the emergency physician. Emerg Med Clin North Am 32(2): 421-435.

36. American Academy of Pediatrics Subcommittee on Hyperbilirubinemia (2004) Management of hyperbilirubinemia in the newborn infant 35 or more weeks of gestation. Pediatrics 114(1): 297-316.

37. Stafstrom CE (1995) Neonatal seizures. Pediatr Rev 16: 248-255.

38.Zupanc ML (2004) Neonatal seizures. Pediatr Clin North Am 51: 961978.

39. Cockburn F, Brown JK, Belton NR, Forfar JO (1973) Neonatal convulsions associated with primary disturbance of calcium, phosphorus, and magnesium metabolism. Arch Dis Child 48(2): 99-108.

40. Maytal J, Novak GP, King KC (1991) Lorazepam in the treatment of refractory neonatal seizures. J Child Neurol 6(4): 319-323.

41. Adamkin DH (2016) Neonatal hypoglycemia. Curr Opin Pediatr 28(2):150-155 